Article

\title{
Extreme Risk Makes the Journey Feasible: Decision-Making amongst Migrants in the Horn of Africa
}

\author{
Oliver Bakewell ${ }^{1, *}$ and Caitlin Sturridge ${ }^{2,3}$ \\ ${ }^{1}$ Global Development Institute, University of Manchester, Manchester, M13 9PL, UK; \\ E-Mail: oliver.bakewell@manchester.ac.uk \\ 2 Department of Development Studies, SOAS University of London, London, WC1H OXG, UK; \\ E-Mail: caitlin_sturridge@soas.ac.uk \\ ${ }^{3}$ Sahan Research, Nairobi, Kenya \\ * Corresponding author
}

Submitted: 30 October 2020 | Accepted: 2 December 2020 | Published: 25 March 2021

\begin{abstract}
This article explores how some potential migrants in the Horn of Africa incorporate the prospects of extreme danger into their journeys. It draws on evidence from qualitative interviews and focus group discussions with over 400 respondents, mainly from Ethiopian and Somali communities. It shows that the risks of migration within the Horn of Africa are often well known, thanks to strong migrant networks and improved mobile communications. Indeed, migrants may be better informed of the risks of the journey than they are about their prospects of securing a good living upon arrival. However rather than discouraging people's migration, high risk may open up new possibilities. This article supports this argument with two examples. First, as Yemen descended into civil war, the breakdown of state control created new opportunities to move undetected, notwithstanding the threat of injury and death. This helps explain why the number of Ethiopians passing through Yemen increased with the conflict, contrary to expectations. Second, some young Somalis are soliciting the services of smugglers to help them move towards Europe, knowing that they are likely to be abused and held for ransom en route. They gamble on their captors' demands being met by family members, who would not otherwise have endorsed or paid for their journey. These findings challenge common assumptions about risk and decision-making, and suggests that some migrants may move because of, rather than in spite of, the risks involved. It also calls into question initiatives that seek to deter migration by raising awareness about the risks of the journey.
\end{abstract}

\section{Keywords}

Ethiopia; human smuggling; information; migration control; risk; Somalia; Yemen

\section{Issue}

This article is part of the issue "Decision-Making under Uncertainty: African Migrants in the Spotlight" edited by Didier Ruedin (University of the Witwatersrand, South Africa / University of Neuchâtel, Switzerland).

(C) 2021 by the authors; licensee Cogitatio (Lisbon, Portugal). This article is licensed under a Creative Commons Attribution 4.0 International License (CC BY).

\section{Introduction}

Migration is an inherently risky process with varying probability of a negative outcome. With this high level of uncertainty, it is impossible to know what lies ahead. The dangers are exacerbated for migrants moving in the context of extreme poverty, insecurity and the absence of rule of law. Risk is generally seen as something to be minimised. Potential migrants need to know about the perils of their journey so they can make an informed decision. Many observers assume that if the risks are too great, the rational choice will be not to move. However, people continue to use the most dangerous routes. This apparently irrational behaviour tends to be explained by two concerns: first, their lack of information about the dangers; second, their assessment of the huge potential gains from migration that outweigh the risks. In this article, we draw on empirical evidence from Puntland 
(Somalia), Djibouti and Yemen to suggest two alternative angles to the issue of risk in migration.

First, this article depicts a clear distinction between migrants and external actors when it comes to their perceptions and evaluations of risk. They are coming from different decision spaces, almost parallel worlds, where there may be occasional points of contact but no way to move from one to the other. This raises questions about what is at risk, and whose version of risk we are taking into account. Second, there is a new twist, where the extreme risk of the journey is used by migrants as a critical element in their migration strategy. In the case of young Somalis seeking routes into Europe, without the risk of kidnapping and death on the way, they would not be able to move. In the case of Ethiopians transiting through Yemen, widespread insecurity generated by the five-year civil war gives them a greater chance of crossing borders undetected. Both groups are acting rationally to achieve their ends-to reach their destination-but the risk they are concerned about is as much that of failing, as that of being injured (physically or mentally) or killed on the way. From this perspective, these dangers may improve their prospects of success.

This article starts by considering the different ways in which risk is conceptualised within the migration literature. This is followed by an overview of migration patterns between the Horn of Africa and Yemen, and beyond, to the Gulf and Europe. Having set the scene, the article goes on to consider the ways in which migrants weigh up risks, suggesting that they are not only aware, but also accepting of the abuse and exploitation they are likely to endure en route to their destination. What is more, while migrants have to tolerate unavoidable risk in this way, in some cases, the extreme dangers open up new opportunities that may facilitate their movement and it may even play a critical role in their decisions about how and where to migrate. In light of these findings, the article raises questions about contemporary migration policies, in particular perceptions around smugglers and the effectiveness of campaigns that provide information about the risks and dangers of migration.

\section{Risk in Migration Studies}

The idea of risk is embedded in different ways within many migration theories. In cost-benefit analysis, the value of factors is discounted depending on the level of risk involved-the benefit of the movement to the city is reduced according to the probability of remaining unemployed or failing to reach the desired level of income (De Jong \& Fawcett, 1981; Harris \& Todaro, 1970). Here, we are concerned with risk that is incurred as a consequence of migration and it moderates the associated calculation of losses and gains.

The new economics of labour migration takes a much broader view, seeing risk as a fundamental aspect of the lives of poor people. Rather than considering risk as a byproduct of moving, new economics of labour migration puts it at the centre of a household's decision-making about migration. It analyses the movement of an individual as part of a household's strategy to diversify its sources of income and thereby spread risk and improve the household's livelihood security (Stark \& Levhari, 1982; Wouterse \& Taylor, 2008). Looking beyond the household, research into networks and transnational connections draws attention to how these wider social structures can help defuse the costs and risks of migration in destination areas by providing assistance to migrants on first arrival, smoothing access to jobs and housing, and so on (Hugo, 1981; Massey, 1990; Portes, 1995).

The literature discussed so far has focused on the risk associated with the outcomes of migration on arrival. Can I secure a job and the income needed to make migration worthwhile? However, there is also a body of literature on the risk associated with the journey. There are two broad strands of analysis here. First, there is research into different migrants' assessment of the risk and their attitude to it. Research into the (non-Jewish) migration from Ecuador to Israel challenges the importance of the household strategy in shaping migrants' decisionmaking. Instead, there is evidence of a more individualist approach to migration and risk from a "new type of migrant" who operates autonomously from family and community, has little established connection to their destination, and makes the decision to migrate hastily and with little information (Kalir, 2005). While these migrants take on the risk of travelling alone, many still connect with transnational networks once they reach Israel.

A second strand of analysis focuses on the nature of the risks faced by migrants on the journey and strategies to mitigate them. This is often framed in terms of protection risks - the likelihood of people's basic human rights being violated, even to the extent of losing lives (Spagna, 2017). These risks are exacerbated when it comes to irregular migration-or more specifically irregular border crossing. This often involves dangerous routes, especially those involving smugglers, and the risks of violence and exploitation are real and well-documented (Busza, Teferra, Omer, \& Zimmerman, 2017; Davy, 2017). Migrants may start their journey by making a contractual agreement with a smuggler to help them cross borders illicitly. All too often, they end up in the hands of traffickers, who cheat, abuse and exploit them to extract maximum profit from the migrants, their families and friends. While both smugglers and traffickers work illegally, and there are often fuzzy boundaries between them, the critical difference is that the former act with the consent of the migrants (clients), while the latter coerces them (victims; Ati, 2017, pp. 7-10).

While recognising this dangerous slippage between smuggling and trafficking, there is an alternative narrative that is built on notions of solidarity and reciprocity, and which recognises the potential social and collective role that smuggling can play in facilitating mobility (Achilli, 2018). This more nuanced narrative has arguably gained momentum in light of the externalisation of EU 
migration policy. Indeed, Ayalew (2018) even suggests that, in the context of a restrictive migration regime that criminalises movement, smuggling can be seen as a "system of refugee protection from below" when safe or legitimate means of mobility are increasingly eroded. Seen from this perspective, it is the state-sponsored efforts to manage migration and prevent migrants from reaching Europe that have created the obstacles to movements that oblige migrants to take more dangerous and risky itineraries - rather than smugglers themselves (Rodriguez, 2019).

It is often assumed that people only take extreme routes when they do not know the full scale of the perilous position in which they are putting themselves. Once informed of the risk - that they may be kidnapped, raped, enslaved, maimed or killed on the way-the rational behaviour is not to migrate in this way. However, a growing number of studies critique this focus on rational behaviour by showing that the significant risks of the journey are well known to migrants, but that this does not deter them from making the journey. In the case of Malian migrants, Dougnon and Gagliardi (2013) argue that migration is not just a rational economic deduction of access to property or earnings-it has deep and powerful cultural ramifications around the realisation of youthful dreams, social aspiration and a rite of passage. Douglas and Wildavsky (1982) also adopt a social constructionist approach that sees risk as determined by culture and open to different social interpretations.

Other studies of risk and migration adopt a gambling analogy, whereby the decision to move is akin to a bet, the outcome of which is seen in terms of luck and the successful conclusion of the journey as "winning the jackpot" (Belloni, 2016). Just as people play the lottery even though the chances of winning are almost zero, the chance-albeit small-of successfully arriving at their destination urges migrants to take the gamble and try their luck, even against high odds of danger and risk (Belloni, 2019).

These approaches can shed light on the failures of sensitisation campaigns that seek to deter migration by spelling out the risks and dangers. If only migrantsor their families as the primary decision-making bodyknew about the dangers, they would act differently. The policy response is to focus on the flow of information to potential migrants and their families. Instead of recognising the cultural embeddedness of migration and alternative local conceptualisations of risk, they categorise those who embark on irregular journeys as reckless or irresponsible-a position vested with moral overtones that has been used to justify repressive measures to stop their journey and criminalise those who help them (Gerver, 2019).

\section{Background to the Study}

Before presenting our findings in more detail, this section gives a brief overview of the background and the methods used for the study, which was undertaken by the Research and Evidence Facility (REF) in 2017. The REF is a research consortium led by SOAS University of London with the University of Manchester and Sahan, a Nairobi-based thinktank in Kenya. It is funded by the EU Emergency Trust Fund for Africa to conduct independent academic research into the drivers of instability, migration, and displacement in the greater Horn of Africa (for more details see the Research \& Evidence Facility website at https://blogs.soas.ac.uk/ref-hornresearch).

The project set out to explore what is driving the growth in migration from the Horn of Africa to Yemen in spite of the risks and dangers. It also assessed the extent to which smuggling and trafficking networks are involved in facilitating these movements, as well as the impact of these movements on the lives of migrants, the local communities and wider society. The full report (Sturridge, Bakewell, \& Hammond, 2017) offers more details of the methods and findings of the study.

The research adopted a comparative approach, looking at migration through the two main routes from Puntland (Somalia) and Djibouti towards Yemen. Teams of local researchers were established in key research sites to identify informants and conduct semi-structured interviews and focus group discussions. In Puntland, the research team focused their work on Bossaso, Qardo and Garowe. In Djibouti, the focus was Djibouti town and Obock. In Yemen, the teams were located in Sana'a, Aden, and Al Hodeidah. Over a six-month period between January and June 2017, the research team consulted over 400 respondents in these locationsincluding migrants, community representatives, people involved in smuggling, government officials, the UN, NGOs and donors. It is hoped that the dataset will be deposited in an archive to made available for further research, subject to ensuring that sufficient contextual information can be removed from transcripts to make them fully anonymous.

In order to ensure comparability of findings, a set of common research questions was drafted by the REF and refined in consultation with the research teams to ensure that the questions were appropriate for each specific research site. Following the data collection, the qualitative data set was coded and analysed along themes initially guided by the original research questions. Each country research team was also responsible for writing a field report that provided a first analysis of their findings. This fed into the overall project report. While the interview guidelines asked respondents what they knew about the risks faced by migrants crossing to Yemen, risk was not a central theme at the outset of the original study. However, through the analysis of the data from the multiple sources, it emerged as a critical factor, sometimes shaping people's movements in counter-intuitive ways, to the extent of opening up new opportunities to move. This article focuses on these new insights into the attitudes of Ethiopian and Somali migrants to risk and the role it played in making possible their journeys towards the Gulf 
and Europe. We have a limited aim of demonstrating that risk does play this strategic role in shaping movement for some, rather than making any claim that this is the case for all. With this in mind, we are drawing on anonymised quotations from a range of respondents that illustrate the points (note, all names used are pseudonyms).

\section{Migration between the Horn of Africa and Yemen}

There is a long history of migration back and forth between the Horn of Africa and Yemen (de Regt, 2014; Thiollet, 2014). The majority of crossings towards Yemen have comprised Ethiopians, Somalis, and Eritreans. For the most part, Ethiopians are moving with the aim of travelling onwards to find work in Saudi Arabia (RMMS, 2016). Many of them are from the Oromo region of Ethiopia, where they have faced political and economic repression including exclusion from employment and seizure of land. The majority are young, single men, often with limited levels of education, but there is a sizeable and growing number of female migrants attracted by the considerable demand for domestic workers in the Gulf states (Fernandez, 2020; Zewdu, 2017). Key informants from multiple agencies including the United Nations High Commissioner for Refugees and the International Organization for Migration (IOM) suggested they could make up 20 to 30 percent of the Ethiopian migrants crossing to Yemen. Indeed, sources in Djibouti suggest that women make up a large percentage of those crossing the border, but they are not seen at the points where people seek assistance and are instead moved in vehicles between smugglers' houses and during the journey carry out domestic work in private homes, which limits their visibility in public spaces.

Over the years, the movement of many Somalis to Yemen has been driven by the need to escape conflict and insecurity and there has long been a Somali refugee population staying in Yemen. Government and NGO key informants observed that, more recently, there has been a growing number of Somalis crossing to Yemen with the aim of reaching Europe, travelling on a convoluted and extremely dangerous route via Yemen back across the Red Sea to Sudan and then through Libya. Their background is more mixed than the Ethiopian migrants, ranging from uneducated people from very poor backgrounds to those with tertiary levels of education and coming from rather wealthy families. There has been less research into which migrants are using this relatively recent route so there is limited knowledge about the numbers or gender distribution (respondents suggested that this route is mostly used by men, but the research team were able to interview almost equal numbers of Somali men and women who were embarking on the crossing to Yemen).

Wherever their origin in the Horn of Africa, few migrants aim to stay in Yemen. Some move relatively quickly on to the next stage of their journey. Others stay on in Yemen for a number of weeks, months and even years, while they work to save up for their next move or recover from illness or destitution. There has also been movement in the opposite direction, most notably among Yemeni refugees fleeing the war that has engulfed their homeland (Mohamud, 2016). Most migration over these routes is undertaken irregularly and under the control of smugglers. African states, supported by donors (including the EU) and international organisations (in particular IOM), have responded to these irregular movements by enforcing new regulations, border controls, cross-border agreements and information campaigns directed towards potential migrants. Saudi Arabia has also been extremely active in deporting irregular migrants from Ethiopia (Fernandez, 2020, p. 30). However, the smuggling and trafficking networks that facilitate these movements have remained resilient and (according to respondents) even increased since 2015, and the numbers of migrants remain high.

With the escalation of the conflict and humanitarian crisis in Yemen in 2015 and 2016, it would have been reasonable to expect a marked fall in the number of people heading to Yemen across the Red Sea and Gulf of Aden. Instead, however, the numbers continued to increase to their highest recorded levels (Botti \& Phillips, 2019; Frouws, 2016). While there could be little doubt that the drivers of out-migration in Ethiopia and Somaliapolitical oppression, insecurity, widespread poverty and drought-continued unabated, it was unclear how the complex array of factors intersected to shape the dynamics of migration between the Horn of African and Yemen. Indeed, the overall picture driving migration was more about the underlying chronic conditions that make it impossible for people to see a desirable future where they are living than with particular or isolated crises. For example, when it came to explaining why they wanted to leave, young Somalis talked first of having no future in Somalia-especially when they had completed what education they could and saw no prospects of getting a job or income that would give them the lifestyle to which they aspired. The immediate crises of drought and insecurity were less prominent as rationales for movement. Only one migrant respondent made explicit reference to the drought in spite of the fact that drought in Somalia during 2016 and 2017 affected over 1.7 million people (OCHA, 2017). Such crises may exacerbate people's sense of frustration and make them more inclined to start on their journey, but they are rarely the primary reason.

\section{Weighing Up the Risks}

Migration between the Horn of Africa and Yemen has long been characterised by danger and risk. Migrants described being increasingly coerced into using smugglers' services, or risk facing detention. They endured deplorable conditions during the journey and upon arrival at their intended destination, suffering from abuse and hardship, illness and death. In addition to frequent reports of abuse, many migrants lack food and 
water, basic services, shelter and livelihoods; difficulties that are compounded by generalised insecurity and an inhospitable climate en route. These dangers are faced by both men and women, but there were also more gender-specific risks. Women were particularly vulnerable to sexual violence, with many referring either to their own or others horrific experiences of rape and other assaults. For men, moving across Yemen brought the potential danger of being caught and conscripted into military service with rebel forces.

Migrants that were interviewed generally knew that the journey was dangerous and involved high risks. Many of the Ethiopian respondents had previous experience as irregular migrants and had spent some time in Saudi Arabia working; they spoke of knowing about the journey already, including the risks it entails:

Because of my previous experience, I know, the biggest risk emerges during sea-travelling; it's a threeday journey with hunger and thirst. If the waves make the boat hard to control, smugglers beat people and offload them forcefully into the sea. (Salim, Ethiopian man, age 25, Bossaso)

Less experienced migrants relied on information from friends and relatives already abroad at their destination. Their pre-departure knowledge was then supplemented by information from other migrants, smugglers and communities they meet along the way. Whatever the source, the expectations were bleak:

I know all the risks, including loss of life, harassment, detention, and so on. (Filan, Ethiopian woman, age 24, Bossaso)

The smuggling group might demand more money when I reach Libya; they might torture me; I could get killed or the inflatable boat sinks; I know the trip is not easy, but I want to do it. (Bashiir, Somali man, age 24, Bossaso)

To me, it was a suicide mission, it was between death and life, but I was ready for it, if lucky I would survive! (Bifani, Ethiopian woman, age 24, Bossaso)

While awareness may encourage migrants to adjust or reconsider which route they take, it is not enough to deter them from migrating in the first place or continuing with their journey once started. Furthermore, migrants are less likely to change their minds about migrating the further they progress along their journey, as the investments and sacrifices increase, and they are reluctant to return empty handed to family back home who may have contributed their savings to make the journey possible. Instead, they take precautionary steps to minimise the consequences of anticipated abuse and exploitation. Some respondents described arranging for family members to keep aside money to pay ransoms to smugglers, while Ethiopian women have been known to take contraceptives to prevent pregnancy if raped:

I knew that I might be arrested by smugglers who ask for ransom, so I prepared my family for that to keep some money aside in that case. (Heeran, Ethiopian man, age 25, Sana'a)

These kinds of safety measures suggest that migrants are not only aware, but also accepting of the abuse and exploitation they are likely to endure. Nearly all Ethiopian migrants described the journey as hard, long and very uncomfortable. They spoke of hunger, thirst, illness and physical danger, including a truck overturning and other accidents on the road. Payments were demanded with menaces, but this was discussed as part of an accepted rough trade, comparable, perhaps, to the way loan sharks exploit their customers' inability to get their service anywhere else, make threats to ensure compliance, but still deliver the service in the end. Being beaten if money is not paid seems to be accepted as a fact of life.

The risks of abuse and exploitation are seen as a necessary part of the journey that migrants must tolerate in order to reach one's destination. Very few saw the risks as outweighing the potential benefit of their journeys. Half of the Ethiopian migrants interviewed in Bossaso felt they were already better off, and the journey was proving worthwhile, even in the face of the hardships. Others were more circumspect, expressing some uncertainty about the final outcome as they were still on the journey. Even among those who said things were worse, only three suggested they would return home if they could. The remarkable sense that things have worked out well in the end despite all the difficulties is illustrated by the responses of Abdi, an Ethiopian man (age 45). In the conversation below, he describes being held hostage with his wife by smugglers who beat him with a metal stick and threatened him with a knife until he agreed to pay the rates they demanded:

Yes, they tortured us, held us hostage for two days and asked our families for ransom money.

[Do you feel you have achieved your objective for moving?] Yes, I am more than happy, since I made my trip to here, now I feel safer.

[What has worked out well?] In an overall sense, all has worked out well.

[What has worked out badly/less well?] Besides the challenges of the trip, the only thing that happened unplanned was the extra money charged.

\section{Seeking Out the Risks}

For the majority of migrants interviewed during this research, the risk of abuse and exploitation is weighed up 
as a necessary means to a more important end-arrival at one's destination. However, while some migrants tolerate unavoidable risk in this way, others seek out risky environments-as the opportunities these present for moving represent a decisive factor in their decisions about how and where to migrate. This relationship between risk and decision-making is highlighted by Ethiopian migrants transiting through Yemen, and, in the most extreme form, by Somali migrants hoping to reach Europe-cases that are now explored in more detail.

As noted above, the escalation of civil war in Yemen has not reduced the number of migrants travelling there. On the contrary, the breakdown of state institutions in Yemen and subsequent lack of policy and control has opened up opportunities for smugglers and traffickers to operate more easily. According to one smuggler respondent:

Before the war in Yemen, our boats used to get fired at by the Yemeni Maritime forces patrolling their sea, but now after the war, we don't encounter any problems-but sometimes ships belonging to the Saudi-led coalition can intercept these boats. (Somali smuggler based in Bossaso)

Similar views were echoed by other key informants, while migrants reported having to take the routes as directed by the smuggler they had contracted. As the situation changes rapidly, these migration routes are adjusted in response to gaps in state control-or take advantage of state actors' fluctuating complicity with smugglers and traffickers. How far these purported gaps in control actually result in an easier journey for migrants, especially for Ethiopians who aim to cross Yemen to reach Saudi Arabia, is unclear. There is limited information about what happens to migrants once they enter Yemen (Frouws \& Akumu, 2016). There seems little doubt that Yemen has become a more dangerous and unpredictable space: a number of Ethiopian respondents were left severely injured after treading on landmines while trying to cross the Yemeni-Saudi border in Sa'dah.

The chaos of war and collapse (or severe degradation) of state systems in Yemen created a space of irregularity-where state controls were absent or more open to manipulation through bribery or other means, and in which smugglers could operate with impunity. Similar spaces have been observed elsewhere, in particular, in Libya, which has generated huge interest as it was seen to open a direct route towards the Mediterranean and Europe (Baldwin-Edwards \& Lutterbeck, 2019). However, this challenge to regular migration is not confined to war zones. Spaces of irregularity can be found in many borderlands across the developing world, where the concept of regularity may be almost meaningless (Bakewell, 2020). To draw a line between regular and irregular migration in such a zone achieves little. Movement continues and there is no means to make it regular-either because there is chaos, as seen in Yemen, or because there is no infrastructure to enable regular movement. If people cannot realistically pass via a border post or nobody has the papers or means to obtain papers to document their movement, how can any crossing be (or become) regular?

For the young Somalis setting off from Bossaso in the hope of reaching Europe, the calculus of risk was very different. They faced similar challenges in navigating spaces of irregularity as the Ethiopians. However, for them, the obstacle to their dreams was not just the state, but also their parents, who did not support their leaving and would not willingly offer them any help for their journey to Europe (for which they cited costs of US\$8-10,000):

[Do you know about anyone else taking actions to control movement-If so who? What do they do?] The only people we fear intercepting us from going is the parents. Once they become suspicious, they immediately communicate with checkpoints over all the possible routes. They also physically visit smugglers hideouts and camps. Parents also use secret intelligence agents for spying. (Zeinab, Somali woman, age 22, Bossaso)

These young migrants had heard the horrific stories of those held to ransom in the desert by traffickers. When asked what she knew about the risks she might face on the journey, a young female respondent listed "torture, rape, killing and extortion." But they see this as a lever to use against their families who did not want them to leave and would not, under normal circumstances, pay for their journey. Many of the Somalis interviewed intended to take up the 'leave now, pay later' scheme increasingly adopted by smugglers to entice would-be migrants, and were not planning to tell their families of their intention to leave. However, they calculated that their relatives would feel compelled to pay the costs of the journey on their behalf, for fear that they would otherwise be subjected to torture and abuse if they did not. If it were simply a question of running out of money, the family may demand that the son or daughter returns home. However, once the youths have committed themselves to the smugglers, the family is trapped into paying for an onward journey, they do not condone and, under normal circumstances, would never have funded. In these cases, it is the risk that makes the journey feasible:

We negotiated the price until we agreed to $\$ 8,000 \ldots . . .1$ didn't pay them; my family has to pay for them when I reach Libya....I didn't tell my family, but they will pay it when they know I am in Libya in the hands of the smuggling group. (Warsame, Somali man, age 22, Bossaso)

It generally costs a maximum of $\$ 10,000$ to reach Europe....But look, I shouldn't worry about that, they [smugglers] are ready to sponsor us till Yemen. From there, then it's up to parents who are forced to pay 
whatever it's going to cost them to rescue me, and they will not force me to come back from that distance. They would rather support me to proceed since I am almost close to the finishing line. (Amaal, Somali woman, age 22, Bossaso)

The remarks made by our respondents suggest something of an inter-generational tussle. Children are prepared to defy their parents and effectively blackmail them to pay for their departure. How this plays out in later life, it is hard to imagine. There is both the huge risk of being hurt, or killed, by trafficking gangs and then that of alienating one's family. The relatives may bail the young people out, but is there a price to be extracted later? Many have reported on the huge efforts many poor African migrants make to send money home from Europe-and the challenges it creates for them in establishing a livelihood there (Lindley, 2010). This is cast in a different light if one looks at the way some young migrants have arranged their journeys at huge, unplanned and unwanted cost to their families.

\section{Incorporating Risk into Migration Policy}

These findings present two challenges to the current response to migration, which are made all the more intractable by the very different perceptions of risk held by the various actors involved. First, it is clear that the relationship with the smugglers is much more nuanced than one of the exploiters and the exploited. They provide a service which is in great demand and, in many cases, they deliver it-at least in as far as getting people across to Yemen. Moreover, their operations, while illegal are deeply embedded in the local political economy, embracing the local authorities, business people and the migrants themselves. While some may create a gateway that leads migrants into the arms of more violent and ruthless traffickers, it is not clear that this is always the case. Not all smugglers are equal. They may all be breaking the law but in spaces of irregularity, where it is almost impossible to move within the law, this does not mean that they are necessarily a primary source of harm to migrants (Gerver, 2019). At times, being under the control of a smuggler may provide a form of protection. This was the case of Mona, an Ethiopian woman who, finding herself stranded without money to pay for the rest of her journey, was forwarded the money by a charitable smuggler:

The smugglers in...asked me to pay an extra amount of money which I did not have, and ordered me to come out of the small transit centre together with some other people whom we had travelled with together. They asked me to come out and follow them but I declined and they tried to pull me out. But things seemed difficult till the other people intervened and fundraised for me some of money. The first smuggler whom I met in...helped me and sent the remaining cash. (Mona, Ethiopian woman, age 33 , Bossaso)

These considerations raise important questions about what the primary aim of interventions should be. Is it to uphold national law? Or is it to uphold the basic human rights of migrants?

Second, these findings on the different ways that migrants assess risk must call into question campaigns to provide information about the risks and dangers of migration. The respondents knew there were risks and many seemed quite matter-of-fact about them. The families are also very aware of the risks and struggle to stop their children from leaving (Ali, 2016, pp. 42-43). Moreover, the smugglers, by offering 'travel now, pay later' deals, have managed to use the danger as a means to increase their custom among young Somalis looking to reach Europe. Migrants' determination to reach their intended destination, even at significant financial and physical cost, meant that awareness of the risks was no deterrent to their movement. This suggests that until young people in the Horn can see a future that enables them to live up to the wider social expectations of contributing to the household and starting their own families, it is a challenge to see how they can be deterred from moving elsewhere. This discussion is often framed as one of European states attempting to impose control on African states (Oette \& Babiker, 2017). We also need to look more closely at the disparity of interests and analysis of risk between generations, where parents and older generations dominate political, economic and social structures.

\section{Concluding Remarks}

There is no doubt that the phenomenon of people embarking on incredibly dangerous journeys in order to move between countries is a huge problem. What is so striking about the risks today is how unnecessary they appear. People have embarked on perilous voyages throughout history, but for the most part the dangers were unknown, unpredictable and unavoidable. There was no safe way to travel from Portugal to the Americas in the 19th century, for instance. However, the work of pioneers at many different levels has helped to reduce the risk faced by future travellers - creating routes, identifying brokers and establishing networks of support services ranging from transport to accommodation. Now it is perfectly physically feasible to move with relative safety to almost any part of the world, if you have the money and it is politically feasible to do so. You have to have the right papers to allow you to travel and for many this is the main stumbling block.

We now have a growing array of stakeholders with an interest in selectively controlling or reducing migrationespecially from poor parts of the world. Others have noted the vicious cycle of increasing border controls and barriers to entry resulting in pushing people into the hands 
of ever more dangerous smuggling groups, creating a migration industry (Gammeltoft-Hansen \& Sørensen, 2013; Schapendonk, 2018). Today, the successful migration of pioneers makes things harder for those who come after them, as routes are shut down, agents apprehended and costs soar. In this game, there is the implicit-or sometimes explicit-calculation that if the costs and risks are made high enough, it will deter people.

However, what this research suggests is that in this calculation there is too much focus on the journey, instead of thinking about the underlying project and its significance. This study points to some more fundamental questions and theoretical debates that need to be taken up. If we want to better understand the role of risk in shaping mobility, we first have to ask what is at risk. As noted above, the existing literature focuses on two main areas: the extreme hazards of the journey and the danger of failing to settle successfully at the destination. Another aspect of risk is that of staying behind. This is often raised in reference to forced migration, where people are subject to threats of death, multiple forms of abuse and other gross violations of their fundamental rights. There is also the structural violence that is evident in the gross inequality, economic and political exclusion that prevents people's flourishing. There is some evidence of both these risks driving young Ethiopians and Somalis to embark on the perilous journey to Yemen.

However, for some of the young people interviewed, migration appears to be a fundamental part of their individual life project. Their primary aim is not to secure their livelihood, or establish themselves abroad, but to live out their lives as fully human. This echoes the findings of Belloni, who analysed decision making for Eritreans migrating to Europe in terms of gambling-they take a bet with very low probability of success, but an extremely high benefit if they are successful (Belloni, 2016). She argues that this 'migration bet' is concerned with finding the conditions to make the transition to adulthood, where one can support the family, marry and have children. Similarly, in West Africa, Dougnon and Gagliardi (2013) found that, for young men in Mali, migration has a deeper cultural significance that defies economic rationality.

For some migrants, the hardships of the journey and the possibility of failing are risks worth taking to obviate the much greater personal risk of being unable to live a full life by not moving. For Ethiopians, this made the risk of moving into the war zone of Yemen worth taking. A more complicated story seems to be emerging for young Somalis engaging on this new convoluted route to Europe. The individuals take the risk to their lives, but they also put at risk the well-being of their families, who not only end up paying their ransom but are also sucked into the trauma of responding to the disappearance of their children. How this plays out in family relationships requires much more research. Ali (2016) has explored this in more detail for the case of young people leaving Somaliland heading north to Europe via Libya. Her work highlights the gap in perception between the generations. Parents who have sufficient resources are investing significant sums to set up their children in businesses to keep them from leaving, often to no avail. However, the 'travel now and pay later' offer from the smugglers enables young people to leave with no immediate cost. They are aware that payment will have to be made, but that future risk is discounted in their minds, so the dire consequences for their families are played down at the point of decision.

Therefore, we not only need to ask what is at risk, but also from whose perspective. It is clear that migrants and their families may have very divergent views. However, unlike Kalir's (2005) 'new type of migrant' that moved independently of the family, here we have migrants being utterly dependent on the family, but the family having very limited say in the decisions and yet facing a huge cost. This raises the question of who bears the risk. Perhaps this is one of the skills of the smugglers and traffickers; not only to move people but also to move some elements of risk away from those who are taking decisions. For the agents deciding to operate in the irregular space of Yemen, they have reduced their own risk of arrest and capture, potentially by putting migrants in greater danger of physical harm from the conflicts. Their 'travel now, pay later' offer enables young Somalis to push the risk into the future and divert it towards their wider families.

While we acknowledge that this is a limited study and these can be seen as extreme cases, they do highlight the polyvalent character of risk in migration. It is ascribed to multiple objects (the journey, the arrival, the life-project), by different actors (the migrants, their parents, smugglers, policymakers) and brings potential costs to the same or other actors. This means it (in its many forms) will act in complex ways to shape migration decisions and outcomes. Here we have shown how extreme risk can facilitate migration. Without making any claim of generalisability, this does challenge much of the analysis that underpins many current theories of migration and policies designed to respond to it. We hope that our ongoing work and that of others will helps to refine our analysis and start filling this critical lacuna.

\section{Acknowledgments}

This article draws on the findings of research undertaken by the Research and Evidence Facility (REF) on migration in the Horn of Africa, which was funded by the EU Trust Fund for Africa (Horn of Africa Window). Their support is gratefully acknowledged. The views expressed in this article are the sole responsibility of the authors and do not necessarily reflect those of the REF or EU. We are particularly indebted to the team of researchers-Farrah Hussein, Hanad Mohamed, Idyle Abdourahman and Wameedh Shakir-who conducted the interviews for this research project in Somalia, Djibouti and Yemen in 2017. We are also grateful for 
the constructive feedback provided by the anonymous reviewers, which greatly helped us in revising the text.

\section{Conflict of Interests}

The authors declare no conflict of interests.

\section{References}

Achilli, L. (2018). The "good" smuggler: The ethics and morals of human smuggling among Syrians. The ANNALS of the American Academy of Political and Social Science, 676(1), 77-96.

Ali, N. (2016). Going on Tahriib: The causes and consequences of Somali youth migration to Europe (RVI Research Paper, 2016/5). Nairobi: Rift Valley Institute. Retrieved from https://riftvalley.net/ publication/going-tahriib

Ati, H. A. A. (2017). Human smuggling and trafficking in Eastern Sudan (Sudan Report SR 2017:2). Bergen: Christian Michelsen Institute. Retrieved from https:// open.cmi.no/cmi-xmlui/handle/11250/2475443

Ayalew, T. M. (2018). Refugee protections from below: Smuggling in the Eritrea-Ethiopia context. The ANNALS of the American Academy of Political and Social Science, 676(1), 57-76.

Bakewell, O. (2020). Undocumented migration and development. In T. Bastia \& R. Skeldon (Eds.), Routledge handbook of migration and development (pp. 74-83). London: Routledge.

Baldwin-Edwards, M., \& Lutterbeck, D. (2019). Coping with the Libyan migration crisis. Journal of Ethnic and Migration Studies, 45(12), 2241-2257.

Belloni, M. (2016). Refugees as gamblers: Eritreans seeking to migrate through Italy. Journal of Immigrant \& Refugee Studies, 14(1), 104-119.

Belloni, M. (2019). The big gamble: The migration of Eritreans to Europe. Oakland, CA: University of California Press.

Botti, D., \& Phillips, M. (2019). Record numbers of refugees and migrants arrive in Yemen amidst intensifying and complicated war. Mixed Migration Centre. Retrieved from http://www.mixedmigration.org/ articles/record-numbers-of-refugees-and-migrantsarrive-in-yemen-amidst-intensifying-andcomplicated-war

Busza, J., Teferra, S., Omer, S., \& Zimmerman, C. (2017). Learning from returnee Ethiopian migrant domestic workers: A qualitative assessment to reduce the risk of human trafficking. Globalization and Health, 13(1). https://doi.org/10.1186/s12992-017-0293-x

Davy, D. (2017). Unpacking the myths: Human smuggling from and within the Horn of Africa (RMMS Briefing Paper 6). Nairobi: Regional Mixed Migration Secretariat. Retrieved from http://regionalmms.org/ images/briefing/RMMS\%20BriefingPaper6\%20\%20Unpacking\%20the\%20Myths.pdf

De Jong, G. F., \& Fawcett, J. T. (1981). Motivations for migration: An assessment and a value expectancy research model. In G. F. De Jong \& Gardner (Eds.), Migration decision making: Multidisciplinary approaches to microlevel studies in developed and developing countries. London: Pergamon Press.

de Regt, M. (2014). Gender, labour and migration between Yemen and the Horn of Africa. In H. Lackner (Ed.), Why Yemen matters: A society in transition (pp. 527-557). London: Saqi.

Douglas, M., \& Wildavsky, A. (1982). Risk and culture: An Essay on the selection of technological and environmental dangers (1 ed.). Berkeley, CA: University of California Press.

Dougnon, I., \& Gagliardi, H. (2013). Migration as coping with risk and state barriers: Malian migrants' conception of being far from home. In A. Kane \& T. H. Leedy (Eds.), African migrations (pp. 35-58). Bloomington, IN: Indiana University Press.

Fernandez, B. (2020). Ethiopian migrant domestic workers: Migrant agency and social change. Cham: Springer International Publishing.

Frouws, B. (2016). Desperate determination: A record number of migrants arrive in Yemen in 2016. Mixed Migration Centre. Retrieved from http://www.mixed migration.org/articles/desperate-determination

Frouws, B., \& Akumu, O. (2016). Pushed and pulled in two directions: An analysis of the bi-directional refugee and migrant flow between the Horn of Africa and Yemen (RMMS Briefing Paper 1). Nairobi: Regional Mixed Migration Secretariat.

Gammeltoft-Hansen, T., \& Sørensen, N. N. (Eds.). (2013). The migration industry and the commercialization of international migration. London: Routledge.

Gerver, M. (2019). Decriminalizing people smuggling. Moral Philosophy and Politics. Advance online publication. https://doi.org/10.1515/mopp-2018-0054

Harris, J. R., \& Todaro, M. R. (1970). Migration employment and development: A two-sector analysis. American Economic Review, 60, 126-142. Retrieved from www.jstor.org/stable/1807860

Hugo, G. J. (1981). Village community ties, village norms and ethnic and social networks: A review of evidence from the Third World. In G. F. De Jong \& R. W. Gardner (Eds.), Migration decision making: Multidisciplinary approaches to microlevel studies in developed and developing countries (pp. 186-224). London: Pergamon Press.

Kalir, B. (2005). The development of a migratory disposition: Explaining a "new emigration." International Migration, 43(4), 167-196.

Lindley, A. (2010). The early morning phonecall: Somali refugees' remittances. Oxford and New York, NY: Berghahn Books.

Massey, D. S. (1990). Social structure, household strategies, and the cumulative causation of migration. Population Index, 56(1), 3-26.

Mohamud, M. (2016). Somalia-Yemen links: Refugees and returnees. Forced Migration Review, (52), 55-56. 
OCHA. (2017). Horn of Africa: Humanitarian impacts of drought-Issue 10. New York, NY: OCHA. Retrieved from https://reliefweb.int/sites/reliefweb.int/files/ resources/HOA_drought_updates_snapshot_ Sep2017_0.pdf

Oette, L., \& Babiker, M. A. (2017). Migration control à la Khartoum: EU external engagement and human rights protection in the Horn of Africa. Refugee Survey Quarterly, 36(4), 64-89.

Portes, A. (Ed.). (1995). The economic sociology of immigration: Essays on networks, ethnicity, and entrepreneurship. New York, NY: Russell Sage Foundation.

RMMS. (2016). Regional mixed migration summary for September 2016 covering mixed migration events, trends and data for Djibouti, Eritrea, South Sudan, Sudan, Ethiopia, Kenya, Puntland, Somalia, Somaliland and Yemen. Nairobi: Regional Mixed Migration Secretariat. Retrieved from http://www. mixedmigration.org/wp-content/uploads/2018/05/ ms-ea-1609.pdf

Rodriguez, A.-L. (2019). European attempts to govern African youths by raising awareness of the risks of migration: Ethnography of an encounter. Journal of Ethnic and Migration Studies, 45(5), 735-751. https://doi.org/10.1080/1369183X.2017.1415136

Schapendonk, J. (2018). Navigating the migration industry: Migrants moving through an African-European web of facilitation/control. Journal of Ethnic and Migration Studies, 4(4), 663-679.

Spagna, G. (2017). Weighing the risks: Protection risks and human rights violations faced by migrants in and from East Africa (RMMS Briefing Paper). Nairobi: Regional Mixed Migration Secretariat.

Stark, O., \& Levhari, D. (1982). On migration and risk in LDCs. Economic Development and Cultural Change, 31(1), 191-196.

Sturridge, C., Bakewell, O., \& Hammond, L. (2017). Migration between the Horn of Africa and Yemen: A study of Puntland, Djibouti and Yemen. London and Nairobi: EU Trust Fund for Africa (Horn of Africa Window), Research and Evidence Facility. Retrieved from https://blogs.soas.ac.uk/ref-hornresearch/files/ 2020/02/HoA-Yemen.pdf

Thiollet, H. (2014). From migration hub to asylum crisis: The changing dynamics of contemporary migration in Yemen. In H. Lackner (Ed.), Why Yemen matters: A society in transition (pp. 491-526). London: Saqi.

Wouterse, F., \& Taylor, J. E. (2008). Migration and income diversification: Evidence from Burkina Faso. World Development, 36(4), 625-640.

Zewdu, G. A. (2017). Ethiopian female domestic labour migration to the Middle East: Patterns, trends, and drivers. African and Black Diaspora: An International Journal, 11(1), 6-19.

\section{About the Authors}
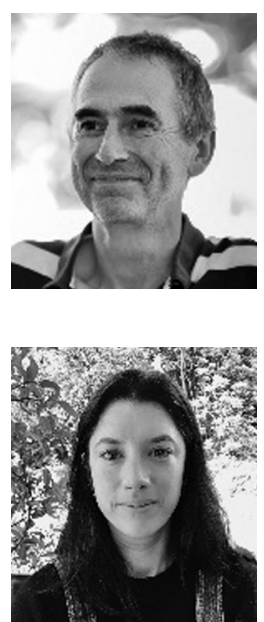

Oliver Bakewell is a Senior Lecturer in Migration Studies at the Global Development Institute, University of Manchester. His work focuses on the intersections between migration and mobility and processes of development and change, with a focus on Africa. Prior to joining the GDI, he spent over a decade at the International Migration Institute at the University of Oxford. He has worked for many years with migrants and refugees both as a researcher and as a practitioner with a range of development and humanitarian NGOs.

Caitlin Sturridge works at the Research and Evidence Facility, a consortium funded by the EU Trust Fund for Africa that conducts research on migration and instability in the Horn of Africa. She completed her MSc in Migration, Mobility and Development at SOAS in 2010 and is currently researching the links between mobility, livelihoods and the environment as part of her PhD at SOAS. 